\title{
Population Dynamics of Thrips on Transgenic and Non-Transgenic Cultivars of Cotton
}

\author{
Saif-ur-Rehman ${ }^{1}$, Jamil Shafi' ${ }^{2, *}$,Waseem Akram ${ }^{1}$, Waqas Ahmad $^{3}$, Muhammad Atiq $^{1}$, Suhail Asad $^{2}$, \\ Muhammad Iqbal
}

\author{
${ }^{1}$ Department of Entomology, University of Agriculture Faisalabad (38040) Pakistan \\ ${ }^{2}$ Department of Plant Pathology, University of Agriculture Faisalabad (38040) Pakistan \\ ${ }^{3}$ Institute of Horticultural Sciences, University of Agriculture, Faisalabad (38040) Pakistan \\ *Corresponding Author: jamil_shafi786@yahoo.com
}

Copyright $(0) 2013$ Horizon Research Publishing All rights reserved.

\begin{abstract}
The present study was performed to evaluate the performance of $\mathrm{Bt}$ and Non-Bt cotton cultivars in response to population fluctuation of thrips in field under RCBD. On the numerical basis results revealed that transgenic cultivars were more susceptible to thrips infestation as compared to conventional genotypes. The pooled comparison of thrips/leaf on different tested cotton cultivars revealed highly significant variations. The results showed that the highest population was observed on IR-901 and FH-113 (3.11 and 3.14 thrips/leaf, respectively) followed by N-121 (2.79 thrips/leaf) and FH-154 (2.78 thrips/leaf). While low level of infestation was observed on CIM-496 and FH-941 (2.20 and 2.18 thrips/leaf, respectively) followed by FH-1000 (2.29 thrips/leaf), FH-207 (2.31 thrips/leaf) and FH-4243 (2.40 thrips/leaf). When data were statistically analyzed thrips population on $\mathrm{Bt}$ and non $\mathrm{Bt}$ cultivars revealed that Bt cotton cultivars had higher level of thrips population (3.8 thrips/leaf) compared to non $\mathrm{Bt}$ cultivars (2.7 thrips/leaf).
\end{abstract}

Keywords Cotton, Thrips Tabaci, Population
Dynamics

\section{Introduction}

Cotton (Gossypium hirsutum L.) is an important cash crop of a number of countries, grown on an area of more than 38 million hectares [1]. Cotton varieties are grown in numerous countries of over five continents [2]. It is an employment generated industry and estimated that about 250 million people are dependent on production, processing and marketing of cotton all over the world. Developing countries provide 50 percent of raw cotton to the developed nations for further processing. Cotton is an important cash crop of Asian countries [3]. Pakistan stands fourth largest producer category of cotton after China, USA and India [4]. Cotton contributes $22.11 \%$ in the national economy by value added products in agriculture and contributed 11 percent to the economy's gross domestic products (GDP) in 2004-05 [5]. More than $70 \%$ of population in Pakistan is designated as rural and approx. $40.7 \%$ are directly engaged in farming. About $25 \%$ of the farmers produce cotton and almost all of them also produce wheat. Almost $70 \%$ of farmers are landowners; the remaining 30\% are sharecroppers or have other tenancy agreements. 46 percent of entire manufacturing sector relies on cotton. Cotton; being a major cash crop provides $38 \%$ of industrial employment, and runs the $31 \%$ of investment sector [6]. In the cotton belt, the general cropping pattern is an alternation in between cotton and wheat. In old days cotton was sown in lines but now a days almost $50 \%$ of cotton growers are adopting new technologies during sowing, growing, protecting and harvesting [7].

Average yield of cotton in Pakistan is about $570.99 \mathrm{~kg} / \mathrm{ha}$, which is very low as compared to other major cotton producing countries of world because of the environment; providing the opportunities for pest outbreaks. Of course, many of the farming practices that enhance yields can also contribute to increased pest problems by providing optimum conditions for pest reproduction, survival and population growth accordingly. Main problem is growing crops as monocultures that provides abundant supply for pest's favorite food [8]. Almost 148 insect pests have been reported during the whole season of cotton; out of which 17 have been designated as major insect pests of cotton crop [9]. Among these insect pests; Jassid (Amrasca devastans Dist.), whitefly (Bemisia tabaci Genn.), Thrips (Thrips Tabaci Lind.) and Aphid (Aphis gossypii Clov.) are very serious insect pests. Magnitude of their damage is very high ranging between $40-50 \%$ [10].

Thrips tabaci damages immature cotton seedlings, flowers and stems. In the beginning of the season attack is severe because of low relative humidity. After its attack leaves of seedlings become wrinkled and distorted, and the vegetative phase is delayed leading to late harvest of the crop causing higher losses not only to the farmer but also to the country's 
economy. Thrips are slender in shape and the color of adults varies from pale yellow to dark brown. Antennae are seven segmented with the first segment always paler than second segment which is usually dark. Pupation occurs in the soil. These are usually active round the year moving from one host to another. Heavy rainfall limits the thrips population. Systemic insecticides; such as seed treatment or sprays offer protection to crop at earlier stages of crop growth [11]. The present study was planned to compare BT and non BT-cotton cultivars for thrips incidence, study the population dynamics and seasonal abundance of Thrips on cotton to identify the peak abundance period.

\section{Materials and Methods}

The experiment was conducted under field conditions keeping all the cultural practices as recommended. Cotton research area of Ayub Agriculture Research Institute, Faisalabad was selected for plantation. Different genotypes of cotton were sown in the start of cropping season of 2011-12. Five transgenic cotton genotypes viz., IR-901, FH-113, FH-4243, FH-154 and N-121, and five non transgenic cultivars viz., FH-207, FH-114, FH-941, FH-1000 and CIM-496, were selected for experimentation. These Bt and non Bt cotton cultivars was selected for experiment because they were locally under cultivation in Punjab, Pakistan. Screening of these cultivars will be very help full for local farmers in choosing best cotton cultivar. Plots of 10 $\times 15$ feet each were prepared for sowing the above said genotypes. Sowing was done with 1.25 feet plant to plant and 2.5 feet row to row distance. During experimentation all the recommended agronomic or cultural practices were adopted, however no chemical treatment or insecticidal sprays were done during the entire cropping period. The crops were planted by following RCBD with three replicates.

The data of thrips population was recorded weekly by zig-zag method. Briefly, fifteen plants were chosen randomly from each replicate. First leaf was from the upper part of the $1^{\text {st }}$ plant, second leaf from middle portion of the $2^{\text {nd }}$ plant, third leaf from lower portion of the third plant and so on, were selected for data recording. The data of population dynamics collected during the entire cropping period of 2011-12 were analyzed by one way analysis of variance using the software MSTAT C, and means were separated by Duncan Multiple Range Test (DMRT).

\section{Results}

\subsection{Population Observation on 01-05-11}

Maximum level of thrips population per leaf was perceived on N 121 (4.10), IR 901 (3.83), FH 154 (3.78) and FH 113 (3.72), all were statistically similar, followed by FH 114 (3.45). while least population was recorded on FH 4243 and FH 207 (2.49, 2.50 thrips/leaf, respectively), both were statistically at par (Figure 1). Pooled comparison of transgenic vs conventional cotton cultivars in relation to population fluctuation of thrips showed that transgenic crops had higher level of thrips infestation (3.58 per leaf) compared to non Bt cotton cultivars (1.87 per leaf) (Figure 2).

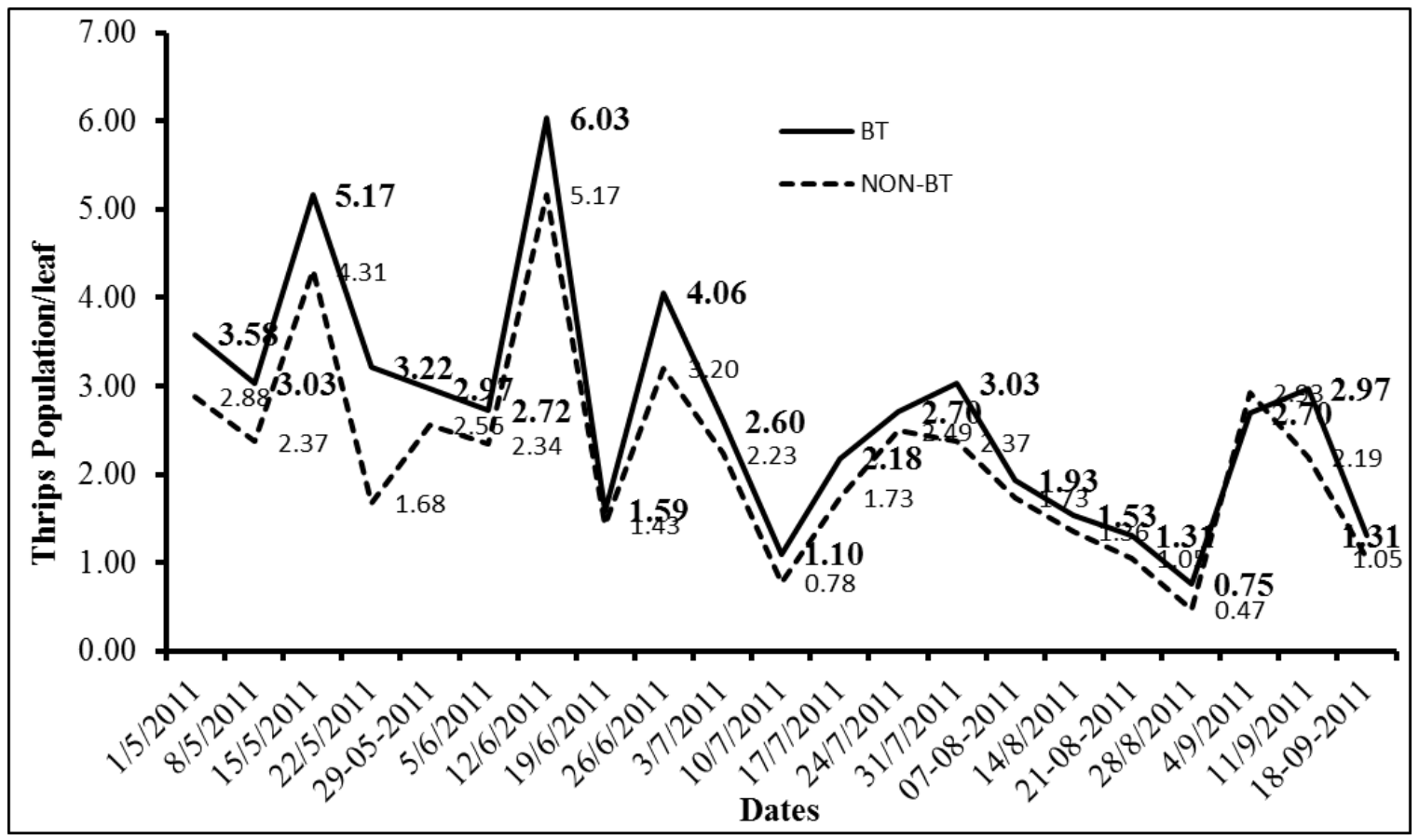

Figure 1. Thrips Population on Different date during the cropping season of 2011-12 


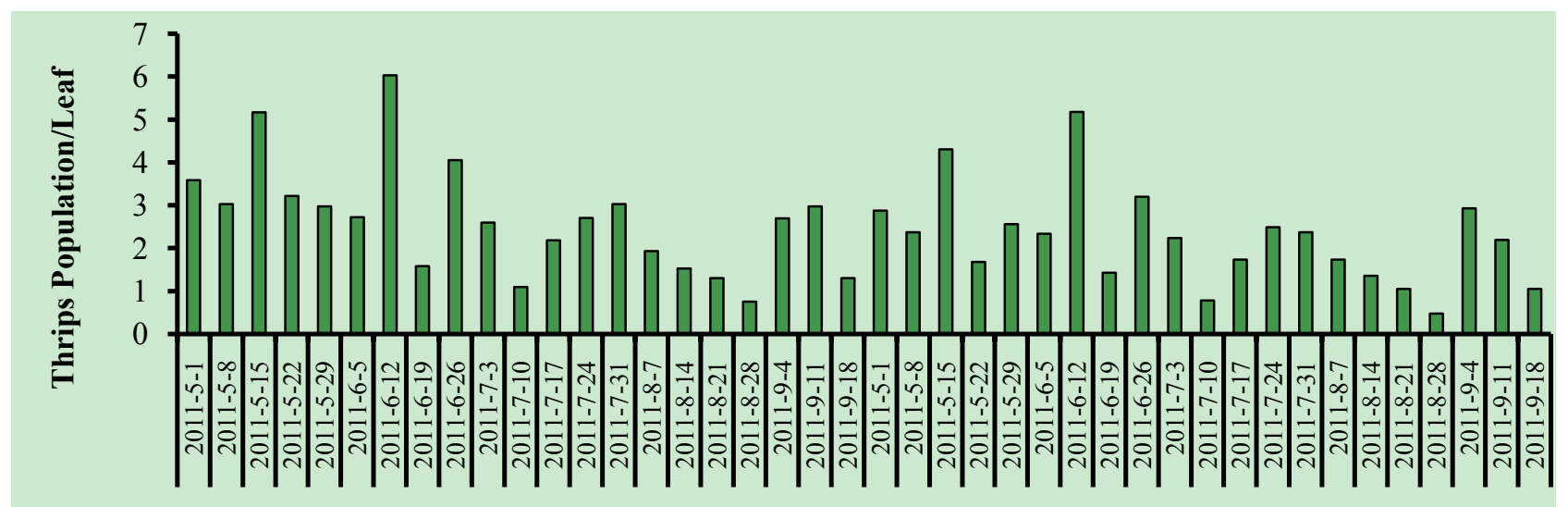

Figure 2. Thrips Population on Different date during the cropping season of 2011-12

\subsection{Population Observation on 08-05-11}

Highest thrips population per leaf was detected on IR 901 (3.30), and FH 113 (3.26), both were statistically at par, followed by FH 154 (3.11). Whereas low level of population infestation was observed on CIM 496 (2.15/leaf) and FH 1000 (2.18/leaf) both were statistically at par, followed by FH 941 (2.31/leaf) (Figure 1). Transgenic crops had higher level of thrips infestation (3.03 per leaf) compared to non $\mathrm{Bt}$ cotton cultivars (2.37 per leaf) (Figure.2).

\subsection{Population Observation on 15-05-11}

Highest level of thrips population per leaf was observed on IR 901 (6.57), followed by FH 113 (4.94) FH 154 (4.82) and FH 4243 (4.82). While minimum population was recorded on CIM 496 (3.67 per leaf) followed by FH 1000 (4.31 thrips/leaf) and FH 941 (4.46 per leaf) ((Figure 1). Transgenic crops had higher level of thrips infestation (5.17 per leaf) compared to non Bt cotton cultivars (4.3 per leaf) (Figure 2).

\subsection{Population Observation on 22-05-11}

Highest level of thrips population per leaf was observed on FH 154 (4.14), and N 121 (4.07), both were statistically at par, followed by FH 4243 (3.83). While low level of population infestation was recorded on FH 941 (0.50) followed by CIM 496 (0.82 per leaf), FH 1000 (0.85 thrips/leaf) and FH 113 (1.04 per leaf), latter were statistically at par ((Figure 1). Transgenic crops had higher level of thrips infestation (3.21 per leaf) compared to non $\mathrm{Bt}$ cotton cultivars (1.68 per leaf) (Figure 2 ).

\subsection{Population Observation on 29-05-11}

Highest level of thrips population per leaf was observed on IR 901 (3.23), FH 113 (3.10) and FH 154 (3.00), all were statistically at par, followed by FH 4243 (2.85). While low level of population infestation was recorded on CIM 496 (2.03 per leaf), FH 1000 (2.03 thrips/leaf) FH 941 (2.12 thrips/leaf) and FH 114 (2.22 per leaf), all were statistically at par (Figure 1). Transgenic crops had higher level of thrips infestation (2.97 per leaf) compared to non Bt cotton cultivars (2.56 per leaf) (Figure 2).

\subsection{Population Observation on 05-06-11}

Highest level of thrips population per leaf was observed on FH 114 (3.10) and N 121 (3.06) followed by FH 154 (2.78), IR 901 (2.78) and FH 113 (2.66). While low level of population infestation was recorded on FH 941 (2.00 thrips per leaf) and CIM 496 (2.07 thrips per leaf), followed by FH 4243 (2.32 thrips/leaf) and FH 1000 (2.24 thrips/leaf), later both were statistically at par (Figure 1). Transgenic crops had higher level of thrips infestation (2.72 per leaf) compared to non Bt cotton cultivars (2.34 per leaf) (Figure 2 ).

\subsection{Population Observation on 12-06-11.}

Highest level of thrips population per leaf was observed on N 121 (7.40) followed by FH 113 (5.81), IR 901 (5.80) and FH 154 (5.79). While low level of population infestation was observed on FH 941 (4.50 thrips per leaf) followed by FH 1000 (5.12 thrips/leaf) and FH 207 (5.34 thrips/leaf), later both were statistically at par (Figure 1). Transgenic crops had higher level of thrips infestation (6.03 per leaf) compared to non Bt cotton cultivars (5.17 per leaf) (Figure 2).

\subsection{Population Observation on 19-06-11}

Thrips population per leaf was maximum on FH 113 (1.75) and FH 114 (1.73), both were statistically at par, followed by and FH 154 (1.69). While low level of population infestation was observed on CIM 496 (1.27 thrips per leaf) and FH 207 (1.29 thrips/leaf), both were statistically at par, followed by FH 941 (1.40 thrips/leaf) and FH 4243 (1.35 thrips/leaf) (Figure 1). Transgenic crops had higher level of thrips infestation (1.59 per leaf) compared to non Bt cotton cultivars (1.42 per leaf) (Figure 2 ).

\subsection{Population Observation on 26-06-11}


Level of thrips population per leaf was highest on IR 901 (5.46), followed by FH 113 (3.83) FH 154 (3.71) and FH 4243 3.70). While minimum population was recorded on CIM (2.56 per leaf) followed by FH 1000 (3.20 thrips/leaf) and FH 941 (3.35 per leaf) (Figure 1). Transgenic crops had higher level of thrips infestation (4.056 per leaf) compared to non Bt cotton cultivars (3.196per leaf) (Figure 2).

\subsection{Population Observation on 03-07-11}

Highest level of thrips population per leaf was observed on IR 901 (2.79) and FH 113 (2.76), both were statistically at par, followed by and FH 154 (2.55) and FH 114 (2.54). While low level of population infestation was observed on FH 1000 (2.00 thrips per leaf) and CIM 496 (2.02 thrips per leaf), both were statistically at par, followed by FH 207 (2.30 thrips/leaf), FH 941 (2.31 per leaf) and FH 4243 (2.39 thrips/leaf) (Figure 1). Transgenic crops had higher level of thrips infestation (2.60 per leaf) compared to non Bt cotton cultivars (2.23 per leaf) (Figure 2).

\subsection{Population Observation on 10-07-11}

Highest level of thrips population per leaf was observed on FH 113 (1.41) and IR 901 (1.39), both were statistically at par, followed by and FH 154 (1.07). While low level of population infestation was observed on CIM 496 (0.62 thrips per leaf), FH 941 (0.63 thrips per leaf) and FH 4243 (0.63), all were statistically at par, followed by FH $207(0.78$ thrips/leaf), FH 1000 (0.93 per leaf) and FH 114 (0.93 thrips/leaf) (Figure 1). Transgenic crops had maximum thrips infestation (1.10 per leaf) compared to non Bt cotton cultivars (0.78 per leaf) (Figure 2$)$.

\subsection{Population Observation on 17-07-11}

Maximum infestation per leaf was observed on FH 113 (2.39), IR 901 (2.35) and FH 154 (2.35), all were statistically at par, followed by and N 121 (2.19). While low level of population infestation was observed on CIM 496 (1.58 thrips per leaf), FH 941 (1.59 thrips per leaf), FH 4243 (1.63) and FH 207 (1.63 thrips per leaf), all were statistically at par, followed by FH 1000 (1.92 thrips/leaf), and FH 114 (1.94 thrips/leaf (Figure 1). Transgenic crops had higher level of thrips infestation (2.18 per leaf) compared to non Bt cotton cultivars (1.73 per leaf) (Figure 2).

\subsection{Population Observation on 24-07-11}

Population per leaf was observed on FH 113 (2.88) and FH 114 (2.86) followed by FH 154 (2.79) N 121 (2.76), later were statistically at par. While low level of population infestation was observed on FH 207 (2.25 thrips per leaf) followed by CIM 496 (2.43 thrips per leaf), FH 1000 (2.45 thrips per leaf), FH 941 (2.47) and FH 4243 (2.47 thrips per leaf) (Figure 1). Transgenic crops had higher level of thrips infestation (2.70 per leaf) compared to non Bt cotton cultivars (2.50 per leaf) (Figure 2).

\subsection{Population Observation on 31-07-11}

Maximumlevel of thrips population per leaf was observed on IR 901 (3.30), and FH 113 (3.26), both were statistically at par, followed by FH 154 (3.11). Whereas low level of population infestation was observed on CIM 496 (2.15/leaf) and FH 1000 (2.18/leaf) both were statistically at par, followed by FH 941 (2.31/leaf) (Figure 1). Transgenic crops had higher level of thrips infestation (3.03 per leaf) compared to non Bt cotton cultivars (2.37 per leaf) (Figure 2).

\subsection{Population Observation on 07-08-11}

Highest thrips population per leaf was observed on $\mathrm{FH}$ 113 (2.07) and IR 901 (2.08), both were statistically at par, followed by FH 114 (1.98), N 121 (1.91) and FH 154 (1.88). While low level of population infestation was observed on FH 207 (1.50 thrips per leaf) followed by FH 941 (1.71 thrips per leaf) and FH 4243 (1.70 thrips per leaf) (Figure 1). Transgenic crops had higher level of thrips infestation (1.93 per leaf) compared to non Bt cotton cultivars (1.73 per leaf) (Figure 2).

\subsection{Population Observation on 07-08-11}

Maximum thrips infestation per leaf was observed on $\mathrm{FH}$ 114 (1.87) followed by IR 901 (1.72), FH 113 (1.67), FH 154 (1.56). While low level of population infestation was observed on CIM 496 (1.51 thrips per leaf), FH 941 (1.17 thrips per leaf) and FH 207 (1.53 thrips per leaf) (Figure 1). Transgenic crops had higher level of thrips infestation (1.65 per leaf) compared to non Bt cotton cultivars (1.36 per leaf) (Figure 2).

\subsection{Population Observation on 21-08-11}

Maximum thrips population per leaf was observed on $\mathrm{FH}$ 113 (1.47) followed by FH 114 (1.40), FH 154 (1.41) and N 121 (1.39). While low level of population infestation was observed on FH 207 (0.85 thrips per leaf) and CIM (0.92), both were statistically at par (Figure 1). Transgenic crops had higher level of thrips infestation (1.31 per leaf) compared to non Bt cotton cultivars (1.05 per leaf) (Figure 2).

\subsection{Population Observation on 28-08-11}

Maximum level of thrips population per leaf was observed on IR 901 (0.85), FH 113 (0.83) and FH 114 (0.80), all were statistically at par. While low level of population infestation was observed on CIM 496 (0.38 thrips per leaf), FH 941 (0.36 thrips per leaf) and FH 207 (0.31 thrips per leaf) (Figure 1). Transgenic crops had higher level of thrips infestation ( 0.75 per leaf) compared to non Bt cotton cultivars ( 0.47 per leaf) (Figure 2$)$. 


\subsection{Population Observation on 04-09-11}

Highest level of thrips population per leaf was observed on FH 207 (3.10), FH 4243 (3.07), FH 1000 (3.00) and FH 941 (2.98), all were statistically at par. While low level of population infestation was observed on $\mathrm{N} 121$ (2.14 thrips per leaf), (Figure 1). Transgenic crops had higher level of thrips infestation (3.00 per leaf) compared to non $\mathrm{Bt}$ cotton cultivars (2.6 per leaf) (Figure 2).

\subsection{Population Observation on 11-09-11}

Highest level of thrips population per leaf was detected from IR 901 (3.23), FH 113 (3.10) and FH 154 (3.00), all were statistically at par, followed by FH 4243 (2.85). While low level of population infestation was recorded on CIM 496 (2.03 per leaf), FH 1000 (2.03 thrips/leaf) FH 941 (2.12 thrips/leaf) and FH 114 (2.22 per leaf), all were statistically at par (Figure 1). Transgenic crops had higher level of thrips infestation (3.00 per leaf) compared to non Bt cotton cultivars (2.6 per leaf) (Figure 2).

\subsection{Population Observation on 18-09-11}

Highest thrips infestation per leaf was observed on FH 113 (1.47) followed by FH 114 (1.40), FH 154 (1.41) and N 121 (1.39). While low level of population infestation was observed on FH 207 (0.85 thrips per leaf) and CIM (0.92), both were statistically at par (Figure 1). Transgenic crops had higher level of thrips infestation (1.37 per leaf) compared to non Bt cotton cultivars ( 0.98 per leaf) (Figure 2$)$.

\subsection{Mean Comparison of Thrips Population on Different Cotton Cultivars During the Cropping Season of 2011-12}

Mean comparison of thrips population per leaf during the entire cropping season is presented By Figer. The results revealed that the highest population was observed on IR 901 and FH 113 (3.11 and 3.14 thrips per leaf, respectively), both were statistically at par, followed by N 121 (2.79 thrips per leaf) and FH 154 (2.78 thrips per leaf). While low level of infestation was observed on CIM 496 and FH 941 (2.20 and 2.18 thrips per leaf, respectively) followed by FH 1000 (2.29 thrips per leaf), FH 207 (2.31 thrips per leaf) and FH 4243 (2.40 thrips per leaf) (Figure 3 ).

\subsection{Mean Comparison of Thrips Population on Different Cotton Cultivars During the Cropping Season of 2011-12}

Among ten cultivars, 5 were Bt cultivars while 5 were non Bt cotton cultivars. The pooled analysis of thrips population on $\mathrm{Bt}$ and non $\mathrm{Bt}$ cultivars revealed that Bt cotton cultivars had higher level of thrips population (3.8 thrips per leaf) compared to non Bt cultivars (2.7 thrips per leaf) (Figure 4).

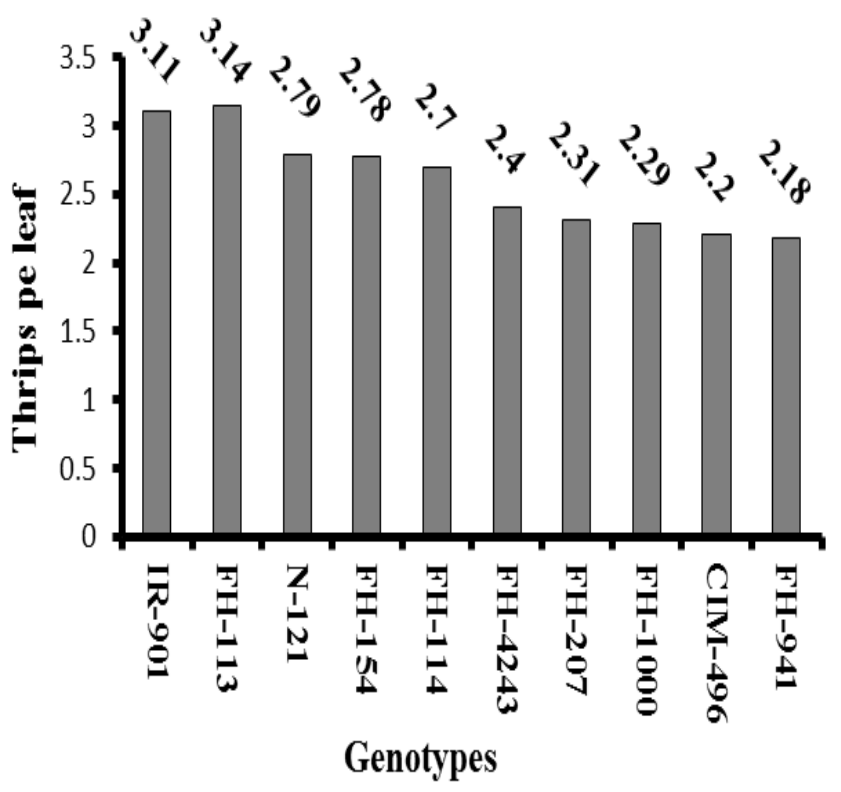

Figure 3. Mean population of thrips on $\mathrm{Bt}$ and non $\mathrm{Bt}$ cultivars during the cropping season of 2011-12

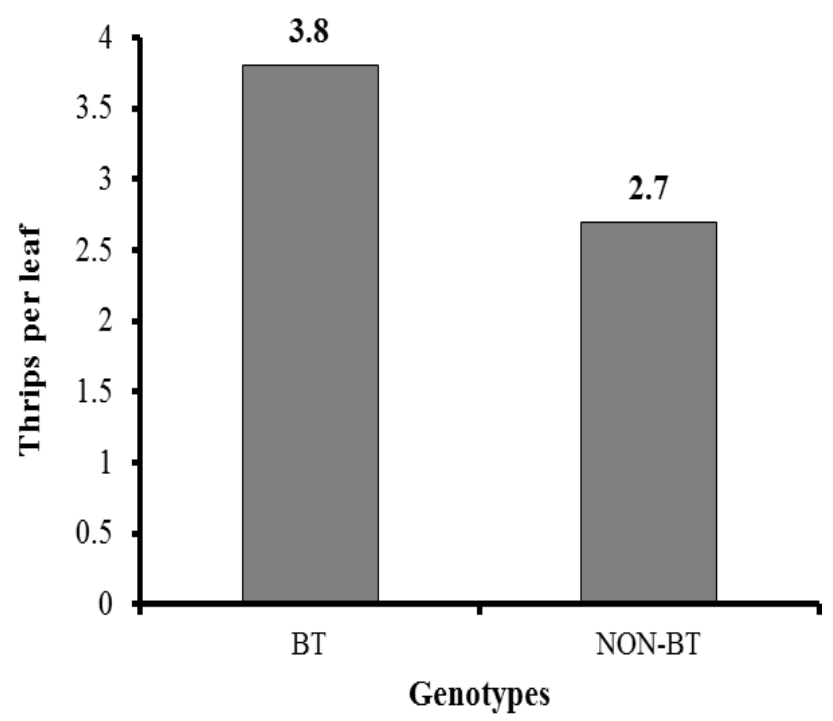

Figure 4. Mean population (pooled) of thrips on Bt and non Bt cultivars during the cropping season of 2011-12

\section{Discussion}

Thrips tabaci is a notorious pest of many crops of economic importance. The results revealed that transgenic cotton cultivars were more susceptible to thrips infestation compared to conventional cotton genotypes. The pooled comparison of thrips per leaf on different tested cotton cultivars revealed highly significant variations. Mean comparison of thrips population per leaf during the entire cropping season revealed that the highest population was observed on IR 901 and FH 113 (3.11 and 3.14 thrips per leaf, respectively), both were statistically at par, followed by $\mathrm{N}$ 
121 (2.79 thrips per leaf) and FH 154 (2.78 thrips per leaf). While low level of infestation was observed on CIM 496 and FH 941 (2.20 and 2.18 thrips per leaf, respectively) followed by FH 1000 (2.29 thrips per leaf), FH 207 (2.31 thrips per leaf) and FH 4243 (2.40 thrips per leaf). The pooled analysis of thrips population on $\mathrm{Bt}$ and non $\mathrm{Bt}$ cultivars revealed that Bt cotton cultivars had higher level of thrips population (3.8 thrips per leaf) compared to non Bt cultivars (2.7 thrips per leaf).

Ricroch and Berge [12], presented a review on the published literature of Bt cotton research. Their focus was to find the reason of why minor pests gained the status of major pests in Bt cotton cultivation. They concluded that before the introduction of Bt crops, broad spectrum insecticidal sprays could effectively control minor pests. With the introduction of $\mathrm{Bt}$ crops major pests were controlled and resultantly frequency and number of insecticidal sprays were reduced tremendously. This practice of reduced pesticidal sprays became the major cause to make minor pests as major pest.

Many researchers have reported the presence of relatively higher number of thrips population on transgenic cotton cultivars compared to non-transgenic cultivars in the past. For instance, Bai [13], Men and Naveen [14] conducted field trials by sowing different $\mathrm{Bt}$ and non $\mathrm{Bt}$ cotton cultivars, for the purpose to assess the level of infestation on these two types of genotypes. They reported that the transgenic cultivars had maximum level of population infestation compared to non-transgenic cultivars. In contrast, some workers reported that transgenic cultivars harbor low level of thrips population per leaf compared to conventional cotton cultivars [15]. While some of the researchers had reported the equal level of infestation of sucking pests including thrips on both Bt and non Bt cotton cultivars. For example, Abro [4], Bambawale [16], Sisterson [17], and Sharma and Pampapathy [18] reported equal level of thrips abundance on transgenic and conventional cultivars. However, the results of our study revealed higher level of thrips population infestation on transgenic cotton compared to conventional cultivars which may be due to host plat susceptibility and favourable environmental factors. Naveen [9] conducted field trials in order to find difference between $\mathrm{Bt}$ and non $\mathrm{Bt}$ genotypes. They concluded that Bt genotypes harbor more number of insects compared to non Bt genotypes. Hofs [20] conducted field trials by planting transgenic and non-transgenic genotypes. They concluded that transgenic genotypes effectively control lepidopterous pests but had no resistance against the attack of different sucking insect pests including jassis, thrips and whiteflies. They further concluded that transgenic genotypes need pesticide spray applications to reduce sucking insect pests.

Arshad and Suhail [21] conducted field trials in an effort to find any difference in the level of infestation by sucking insect pests on $\mathrm{Bt}$ and non $\mathrm{Bt}$ cotton cultivars. For this purpose they sowed two cotton genotypes viz., IR-FH-901 (a genotype having Crylac toxin) and its parent variety FH-901, which was a non $\mathrm{Bt}$ cultivar. They monitored the populations of jassid, whitefly and thrips weekly on the above said genotypes. In conclusion, they concluded that there was a non-significant difference with regards to level of sucking pests infestation on both types of genotypes.

Ali and Mumtaz [22] performed field experiments to evaluate the level of resistance or susceptibility of different locally available cotton genotypes and population dynamics of sucking insect pests. They tested eight cotton genotypes viz., FH-901, CIM-707, N-111, CIM-499, SLH-279, BH-160, BH-1199 and BH-335. Whereas three sucking insect pests viz, whitefly, jassid and thrips were the focus to study population dynamics on the above said genotypes. They concluded that the tested genotypes had non-significant difference concerning level of infestation of different sucking pests.

Bashir [23] conducted field trials to evaluate the performance of different cotton genotypes under field conditions. The selected genotypes were as under: HR-138, Brown, camel brown, HR-109, HR-127, Green, VO-MS, NIAB, Krishma and CIM-448. Besides studying population dynamics of sucking pests on these cultivars, they also investigated the morphological leaf traits of these varieties. They concluded that genotypes were significantly different in response to infestation of different sucking pests like whitefly, thrips and jassids. Moreover they concluded positive association of thrips with hair density of leaves.

Panicker and Patel [24] conducted a series of field investigation for the sake to manage thrips. They focused on three crops viz., pigeon pea, chili and cotton. Different genotypes of these crops were sown for study purpose. They concluded that genotypes were different in their response to fluctuate thrips population.

Rehman [25] conducted field trials to assess the relative host plant resistance against different sucking insect pests. He tested eight cotton genotypes: BH-147, SLH-244, SLH-257, BH-124, BH-125, BH-121 and NIAB-98. He recorded weekly observations of incidence of three sucking insect pests including jassid, thrips and whitefly. He concluded that the cultivar BH-121 was comparatively more susceptible to sucking pest attack compared to the rest of cultivars.

Men [14] reported that Bt crops could effectively control major pests of cotton. Resultantly, low pesticide usage on these crops could enhance the populations of minor pests.

\section{REFERENCES}

[1] M. Kannan, S. Uthamasamay, S. Mohan. Impact of insecticides on sucking pests and natural enemy complex of transgenic cotton, Current Science, Vol.86, No.5, 726-729, 2004.

[2] M. Afzal, M. M. Ali. History of cotton: Cotton Plant in Pakistan, Aiwan-I-Science publisher, Pakistan, 1983.

[3] Z. Ahmad. Pest Problems of Cotton, A Regional Perspective', Proceedings of ICAC-CCRI, Regional Consultation 
Insecticide Resistance Management in Cotton, Pakistan, 1999.

[4] G. H. Abro, T. S. Syed, G. M. Tunio, M. A. Khuhro, 2004. Performance of transgenic Bt cotton against insect pest infestation. Biotechnology, Vol.3, No.1, 75-81, 2004.

[5] N. Naqvi, Nausheen. Statistical supplement of economic survey, Available online from http://www.finance.gov.pk/ admin/images/survey/chapters/Chapter, 2008.

[6] A.M. Jalal, M. D. Gogi, M. Mirza, K. Zia, F. Hafeez. Impact of Plant Spacing and Abiotic Factors on population dynamics of sucking insect pests of cotton, Pakistan Journal of Biological Sciences, Vol.9, No.7,1364-1369, 2006.

[7] M. Yasin. 2005. The preparation and use of spray machinery, Directorate of Agriculture Information, Pakistan, 2005.

[8] K. Bakhsh, I. Hassan, A. Maqbool. Factors affecting cotton yield, Journal of Agriculture and Social Sciences, Vol.1, No.4, 332-334, 2005.

[9] M. A. Abbas, M. A. General Agriculture. Publ. Emporium, $2^{\text {nd }}$ (Ed.), Pakistan. 2004

[10] K. M. Naqvi. 1976. Crop protection to boost up cotton production. Proc. Cotton Prod. Sem.,orgnised by ESSO Fert. Co.Ltd.,Pakistan, 1976.

[11] P. D. Colyer, S. Mininski, P. R. Vernon. Effect of thrips infestation on the development of cotton seedling diseases, Plant Diseases, Vol.75, 380-382, 1991.

[12] A. Ricroch, J. B. Bergé, M. Kuntz. 2010. Is the German suspension of MON810 maize cultivation scientifically justified?, Transgenic Research, Vol.19, No.1, 1-12, 2010 .

[13] L. X. Bai, Z.L. Wa, C.X. Bo, F.J. Jin, G.G. Hua, Z.Z. Qing, S. Chune. Preliminary studies on effects of transgenic cotton varieties on composition of insect community. Chinese Journal of Biology, Vol.18, 115-119, 2002.

[14] X. Y. Men, F. Ge, E. Yardim, M. N. Parajulee. Behavioral response of Helicoverpa armigera (Lepidoptera: Noctudae) to cotton with and without expression of the CryIAc delta-endotoxin protein of Bacillus thuringiensis Berliner. Journal of Insect Behavior, Vol.18, No.1, 33-50, 2005.

[15] M. E. A. Whitehouse, L. J. Wilson, G. P. Fitt, 2005. A comparison of arthropod communities in transgenic Bt and conventional cotton in Australis, Environmental Entomology.
Vol.34, No.5, 1224-1241, 2005.

[16] O. M. Bambawale, A. Singh, O. P. Sharma, B. B. Bhosle, R. C. Lavekar, A. Dhandapani, V. Kanwar, R.K.Tanwar, K. S. Rathod, N. R. Patange, V. M. Pawar. 2004. Performance of $B t$ cotton (MECH-162) under Integrated Pest Management in farmers' participatory field trial in Nanded District, Central India. Current Science, Vol.12, No.25, 1628-1633, 2004.

[17] M. S. Sisterson, R. W. Biggs, C. Olson, Y. Carrie' re, T.J. Dennehy, B.E. Tabashnik. Arthropod abundance and diversity in $\mathrm{Bt}$ and non-Bt cotton fields. Environamental Entomology, Vol.33, No.4, 921-929, 2004.

[18] H. C. Sharma, G. Pampapathy. Influence of transgenic cotton on the relative abundance and damage by target and non-target insect pests under different protection regimes in India. Crop Protection, Vol.25, No.8, 800-813, 2006.

[19] A. Naveen, D. S. Brar a, G. S. Butter. Evaluation of Bt and non Bt version of two cotton hybrids under different spacing against sucking insect pests and natural enemies. Journal of Cotton Research and Development, Vol.21, No.1, 106-110, 2007.

[20] J. L. Hofs, A. Schoeman, M. Vaissayre, 2004. Effect of Bt cotton on arthropod biodiversity in South African cotton fields. Communication of Agriculture and Applied Biological Sciences, Vol.69, No.3, 191-194, 2004.

[21] M. Arshad, A. Suhail. Studying the sucking insect pests community in transgenic Bt cotton. International Journal of Agriculture and Biology, Vol.12, 764-768, 2010.

[22] A. Ali, M. K. Mumtaz, Integration of chemical control and host plant resistance in cotton against weed pest complex. Pakistan Entomology, Vol.35, No.3, 221-225, 1999.

[23] M. H. Bashir, M. Afzal, M. A. Sabri, Abu Bakar M. Raza. 2001. Relationship between sucking insect pests and physico morphic plant character towards resistance/susceptibility in some new genotypes of cotton, Pakistan Entomology, Vol.23, No.2, 75-78, 2001.

[24] B. K. Panickar, J. B. Patel. Population dynamics of different species of thrips on chilli, cotton and pigeon pea, Indian Journal of Entomology, Vol.63, 170-175, 2001.

[25] M. L. Rehman. Effect of interaction of some weather factors and genotypes on population of sucking insect pests of cotton. M.Sc. Thesis. Deptt. Entomol. Faculty of Crop Protection Sciences NWFP Agriculture University, Peshawar, Pakistan, 2002 